EDITORIAL

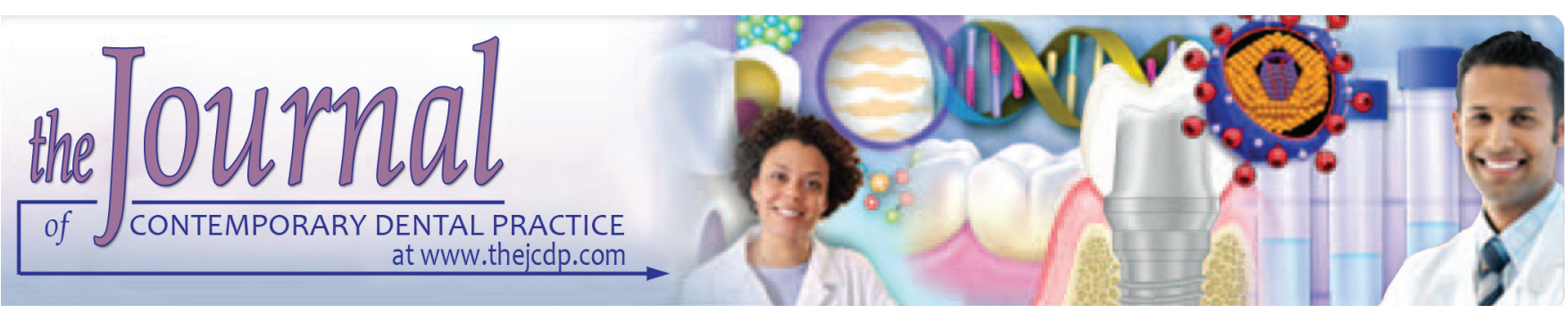

\title{
Oral Health Hazards of Water Pipe Smoking: Current Evidence
}

\author{
${ }^{1}$ A Thirumal Raj, ${ }^{2}$ Shankargouda Patil, ${ }^{3}$ Sachin Sarode, ${ }^{4}$ Gargi Sarode
}

How to cite this article: Raj AT, Patil S, Sarode S, Sarode G. Oral Health Hazards of Water Pipe Smoking: Current Evidence. J Contemp Dent Pract 2017;18(7):539-540.

\section{Source of support: Nil}

Conflict of interest: None

\section{INTRODUCTION}

Water pipe smoking (WPS) has been a traditional habit in the Middle Eastern Society for hundreds of years. The WPS users have a false sense of safety due to its casual use in social gatherings. It was estimated that about 70\% of WPS users believe it to be a safe alternative to cigarette smoking. ${ }^{1}$ Further, the use of flavored tobacco has led to its growing popularity, especially among youngsters.

The World Health Organization (WHO) study group on "Tobacco Product Regulation" had published an advisory note on the possible health hazards of WPS. The note states the similarity between cigarette smoking and WPS. ${ }^{2}$ Several carcinogens from cigarette smoking like polycyclic aromatic hydrocarbons, volatile aldehydes, phenols, and heavy metals are also a part of WPS. ${ }^{3}$ Further, it was observed that the duration of one WPS session far exceeds that of smoking one cigarette. The

\footnotetext{
${ }^{1}$ Department of Oral Pathology and Microbiology, Sri Venkateswara Dental College and Hospital, Chennai, Tamil Nadu, India

${ }^{2}$ Division of Oral Pathology, Department of Maxillofacial Surgery and Diagnostic Sciences, College of Dentistry, Jazan University Jazan, Kingdom of Saudi Arabia

${ }^{3,4}$ Department of Oral Pathology and Microbiology, Dr. D. Y. Patil Dental College \& Hospital, Dr. D.Y. Patil Vidyapeeth, Pune Maharashtra, India

Corresponding Author: A Thirumal Raj, Department of Oral Pathology and Microbiology, Sri Venkateswara Dental College and Hospital, Chennai, Tamil Nadu, India, e-mail: thirumalraj666@gmail.com
}

increased dosage of WPS in relation to cigarette smoking is well established with the WHO equating 1 WPS session to smoking 100 cigarettes or more. $^{2}$

Several individual studies and systematic reviews have linked WPS to cancer and respiratory and cardiovascular diseases. Children born to mothers using WPS have shown to exhibit respiratory and mental health disorders. Communicable diseases are common in WPS due to shared water pipes. ${ }^{4,5}$

In addition to the above-mentioned systemic health hazards, WPS has shown detrimental effects on the oral cavity. Akl et $\mathrm{al}^{4}$ published a systematic review examining the health hazards posed by WPS. The study showed a strong association between WPS and high plaque and gingival indices, significant bone loss, attachment loss, and development of periodontal pockets. An Egypt-based study evaluated 300 males (100 non-smokers; 100 cigarette smokers; 100 water pipe smokers). All the patients underwent extraction of the third molar under local anesthesia. The result showed that water pipe smokers had three times greater risk of developing dry socket than nonsmokers. It was also observed that there was no statistically significant difference in the risk of developing dry socket between cigarette smokers and WPS users. ${ }^{6}$

Although several systematic reviews have associated WPS with cancer, especially lung cancer, its role in oral carcinogenesis is still debated. ${ }^{7,8} \mathrm{Al}$-Amad et $\mathrm{al}^{9}$ found that WPS may cause cancer early in younger individuals (46 years in males and 43.8 years in females in comparison to a relatively older age group of 62.1 and 63.5 years in nonsmoking males and females respectively), which may be due to the rampant use of WPS among youngsters. But studies exploring WPS association with oral cancer have failed to account for the concomitant use of tobacco and alcohol.

Based on the similarity of WPS with cigarette smoking (shared carcinogens) and relatively increased dosage level with the former, it can be hypothesized that WPS is 
potentially carcinogenic. Conclusive evidence of the same can be obtained from case-control and cohort studies with exclusively WPS users. Molecular studies examining the effects of chronic WPS use on the oral tissue will aid in unveiling the molecular pathway of WPS-induced carcinogenesis. Data from such molecular studies would aid in identifying key diagnostic and therapeutic targets.

To conclude, WPS is a public health hazard and is more hazardous than cigarette smoking. Thus, it is vital to curb the rampant use of WPS using social and mediabased interventions, especially among youngsters.

\section{REFERENCES}

1. Warnakulasuriya S. Waterpipe smoking, oral cancer and other oral health effects. Evid Based Dent 2011;12(2):44-45.

2. WHO study group on Tobacco Product Regulation (TobReg). Advisory Note. Waterpipe tobacco smoking: health effects, research needs and recommended actions by regulators. 2005.

3. Primack BA, Carroll MV, Weiss PM, Shihadeh AL, Shensa A, Farley ST, Fine MJ, Eissenberg T, Nayak S. Systematic review and meta-analysis of inhaled toxicants from waterpipe and cigarette smoking. Public Health Reports. 2016 Jan-Feb; 131(1):76-85.

4. AklEA, GunukulaSK,AleemS, Obeid R, Jaoude PA,Honeine R, Irani J. The prevalence of waterpipe tobacco smoking among the general and specific populations: a systematic review. BMC Public Health 2011 Apr;11:244.

5. Kim KH, Kabir E, Jahan SA. Waterpipe tobacco smoking and its human health impacts. J Hazard Mater 2016 May;317: 229-236.

6. Fouad A. Al-Belasy J. The relationship of "shisha" (water pipe) smoking to postextraction dry socket. Oral Maxillofac Surg 2004 Jan;62(1):10-14.

7. Mamtani R, Cheema S, Sheikh J, Mulla A, Lowenfels A, Maisonneuve P. Cancer risk in waterpipe smokers: a metaanalysis. Int J Public Health 2017 Jan;62(1):73-83.

8. Awan KH, Siddiqi K, Patil S, Hussain QA. Assessing the effect of waterpipe smoking on cancer outcome - a systematic review of current evidence. Asian Pac J Cancer Prev 2017 Feb;18(2):495-502.

9. Al-Amad SH, Awad MA, Nimri O. Oral cancer in young Jordanians: potential association with frequency of narghile smoking. Oral Surg Oral Med Oral Pathol Oral Radiol 2014 Nov;118(5):560-565. 